\title{
Body mass, fat percentage, and fat free mass as reference variables for lung function: effects on terms for age and sex
}

\author{
J E Cotes, D J Chinn^, J W Reed
}

\begin{abstract}
Background-Sex specific cross sectional reference values for lung function indices usually employ a linear model with terms for age and stature. The effects of also matching for body mass index (BMI = mass/stature ${ }^{2}$ ) or its components, fat percentage of body mass (fat $\%$ ) and fat free mass index (FFMI = fat free mass/ stature $^{2}$ ) were studied.

Methods-The subjects were 458 asymptomatic male and female non-smokers (383 men) and 22 female ex-smokers. Measurements were made of ventilatory capacity, lung volumes, transfer factor (diffusing capacity, single breath $\mathrm{CO}$ method), and body composition (skinfold method). Linear and proportional regression models were used.
\end{abstract}

Results-Terms for fat $\%$ and FFMI significantly improved the accuracy of reference values for all the primary lung function indices. The improvements in subjects with atypical physiques (fat $\%$ and FFMI at the ends of the distributions for the subjects) were in the range 0.3-2.3 SD compared with conventional regression equations. The new partial regression coefficients on age were independent of age related changes in body fat. The coefficient for total lung capacity (TLC) on age in men was now positive. Most differences between the sexes were eliminated. A term for BMI improved the descriptions of subdivisions of TLC but lacked the other advantages.

Conclusion-Allowance for fat $\%$ and FFMI increases the accuracy of reference equations for lung function, particularly for subjects with a lot of fat and little muscle or vice versa. Allowance for BMI is less informative.

(Thorax 2001;56:839-844)

Keywords: lung function; body composition; reference values; body mass index

Postgraduate Institute for

Health, University of

Teesside, Middlesbrough

TS1 3BA, UK

Correspondence to:

Dr J E Cotes

Coterie@globalnet.co.uk

Received 20 November 2000

Returned to authors

15 February 2001

Revised version received

5 July 2001

Accepted for publication

26 July 2001 Most cross sectional equations for describing lung function in men and women separately use an additive linear model containing terms for age and stature. ${ }^{12}$ Body mass is seldom used except for functional residual capacity. ${ }^{1-3}$ This study explores the contributions to lung function measurements of body mass and its fat and fat free components derived from skinfold measurements. ${ }^{4}$
A reduction in body fat is associated with an increase in lung volume, but the improvement is often modest. ${ }^{5}$ In women this is partly due to much of the additional fat being distributed peripherally, whereas in obese men the fat is distributed more centrally. ${ }^{6}$ As a result, the effect on vital capacity of a change in body mass is larger in men than in women. ${ }^{7}$ In a recent cross sectional study the difference in forced vital capacity (FVC) between the sexes was reduced when waist circumference was taken into account. $^{8}$

The fat free component of body mass can be expressed relative to body size as fat free mass index $\left(\right.$ FFMI = fat free mass/stature $\left.{ }^{2}\right)$. Much of it is muscle and is augmented by physical training, including training of respiratory muscle. ${ }^{9}$ Such training is a feature of deep sea divers and rowers, and contributes to participants in these activities often having a relatively large vital capacity. ${ }^{2}{ }^{10}$ Load carrying may also have a training effect and could contribute to the lung function of some subjects being well preserved even when obese. ${ }^{11}$

These observations show that changes in both fat and muscle can affect the lungs; however, they can have the opposite effect on vital capacity and possibly other indices so that, when they are considered together as mass, the two effects can cancel each other out. The use of separate terms for fat and muscle improve descriptions of FVC measured cross sectionally $^{812-14}$ and of changes in forced expiratory volume in one second $\left(\mathrm{FEV}_{1}\right)$ and FVC estimated longitudinally. ${ }^{15}$

In this study we applied linear and proportional models that include body composition to population data for indices of ventilatory capacity, lung volumes, and transfer factor in white men and women to test the hypothesis that differences in body composition between individuals, between age groups, and between the sexes can explain some of the features of lung function that are now attributed respectively to random variation, age, and sex.

\section{Methods}

Published lung function findings for healthy subjects were volunteers who considered themselves healthy; none admitted to regular cough, phlegm, or breathlessness. The men (383 shipyard workers) were physically active on account of their occupation. They were lifetime nonsmokers (less than one cigarette per day for a year). The women (97 from a range of occupations) agreed to perform a progressive exercise 
Table 1 Description of subjects (mean values and ranges for primary indices)

\begin{tabular}{|c|c|c|}
\hline & Women $(n=97)$ * & $\operatorname{Men}(n=186) \dagger$ \\
\hline Age (years) & $47.8(25-74)$ & $35.2(25-63)$ \\
\hline Stature $(\mathrm{St}, \mathrm{m})$ & $1.60(1.45-1.77)$ & $1.73(1.48-1.91)$ \\
\hline Body mass index $\left(\mathrm{BMI}, \mathrm{kg} / \mathrm{m}^{2}\right)$ & $24.9(17-37)$ & $25.3(20-40)$ \\
\hline Body fat percent of body mass (fat $\%$ ) & $36.7(17-47)$ & $19.3(7-37)$ \\
\hline Fat free mass index (FFMI, $\mathrm{kg} / \mathrm{m}^{2}$ ) & $15.6(12-22)$ & $20.3(17-30)$ \\
\hline Forced expiratory volume $\left(\mathrm{FEV}_{1}, 1\right)$ & $2.54(1.0-3.8)$ & $3.88(1.6-5.7) \dagger$ \\
\hline Forced vital capacity $(\mathrm{FVC}, 1)$ & $3.25(1.3-5.2)$ & $5.04(2.6-7.1) \dagger$ \\
\hline Total lung capacity (TLC, 1 ) & $5.21(3.5-7.9)$ & $6.70(4.1-9.4)$ \\
\hline Inspiratory capacity $(\mathrm{IC}, 1)$ & $2.41(0.9-3.7)$ & $3.42(1.7-4.9)$ \\
\hline Functional residual capacity (FRC, 1) & $2.80(1.6-4.6)$ & $3.28(1.5-5.9)$ \\
\hline Expiratory reserve volume (ERV, 1$)$ & $1.12(0.3-2.3)$ & $1.82(0.3-3.9)$ \\
\hline Residual volume (RV, 1 ) & $1.68(0.8-2.7)$ & $1.46(0.6-3.2)$ \\
\hline Transfer factor (TLCO, $\mathrm{mmol} / \mathrm{min} / \mathrm{kPa})$ & $8.9(4.9-14.4)$ & $12.0(6.9-16.2)$ \\
\hline $\mathrm{VA} / \mathrm{St}^{2}$ & $1.94(1.3-2.4)$ & $2.15(1.6-2.8)$ \\
\hline
\end{tabular}

${ }^{\star}$ Mean values differed from those in men $(\mathrm{p}<0.05)$.

$t_{n}=383$ for $\mathrm{FEV}_{1}$ and $\mathrm{FVC}$ (mean reference variables in appropriate units: age 38.1, stature 1.73, BMI 25.4, fat $\%$ 20.3, FFMI 20.2).

Table 2 Intercorrelations between principal reference variables (non-significant correlations $(p>0.05)$ are in parentheses)

\begin{tabular}{|c|c|c|c|c|c|}
\hline & \multicolumn{5}{|l|}{ Men } \\
\hline & Age & Stature & $B M I$ & $\mathrm{Fat} \%$ & $F F M I$ \\
\hline \multicolumn{6}{|l|}{ Women } \\
\hline Age & & -0.20 & 0.31 & 0.69 & -0.14 \\
\hline Stature & -0.24 & & $(-0.07)$ & $(-0.04)$ & $(-0.07)$ \\
\hline BMI & 0.28 & -0.21 & & 0.68 & 0.80 \\
\hline Fat $\%$ & 0.71 & -0.29 & 0.71 & & 0.12 \\
\hline FFMI & -0.24 & $(-0.05)$ & 0.81 & $(0.12)$ & \\
\hline
\end{tabular}

test. They included 22 ex-smokers (no cigarettes for $>6$ months) as the term for ex-smoking was not significant in a preliminary analysis.

\section{MEASUREMENTS}

All subjects had completed a respiratory questionnaire with additional questions on habitual activity, submitted to anthropometric measurements, and performed dynamic spirometric tests. Static lung volumes and transfer factor for carbon monoxide were available for the women and for 186 men. Maximal inspiratory and expiratory pressures were available for 157 men.

Body mass and stature were used to calculate body mass index (BMI = body mass/stature $\left.{ }^{2}\right)$. The fat $\%$ and FFMI components were calculated using the method of Durnin and Womersley from body mass and measurements of four skinfolds. ${ }^{4}$

Dynamic spirometric tests were performed using a dry bellows digital spirometer. In the men the procedure was that of the European Coal and Steel Community ${ }^{1}$ while, in the women, it was similar except that there was no back extrapolation. To allow for this, the data for $\mathrm{FEV}_{1}$ in women were corrected retrospectively by a factor of $1.025 .^{2}$

Transfer factor (TLCO) was measured by the single breath method and total lung capacity and subdivisions by multiple breath helium dilution. Practical details of the methods, including calibration, are given elsewhere. ${ }^{2} 1215$

The studies were approved by the appropriate ethical committees.

\section{ANALYSIS OF DATA}

The contribution of body composition to the description of individual indices of lung function was assessed by multiple regression analysis (sPSs) using linear and proportional models with stepwise and fixed entry of the reference variables. For TLCO and transfer coefficient $(\mathrm{KCO}=$ TLCO/alveolar volume $(\mathrm{VA})$ ) the variables included alveolar volume/stature ${ }^{2}$ $\left(\mathrm{VA} / \mathrm{St}^{2}\right) .{ }^{16}$ The effect of allowing for body composition on the partial regression coefficients on age and on sex were analysed using the same reference variables in both equations. Sex was a categorical variable and a component of interaction terms with age, stature and fat $\%$. The age/sex interaction was retained where it was significant $(p<0.05)$. For coefficients on body composition, in order to reduce the risk of type 2 errors, only the $1 \%$ level of probability was accepted without qualification. Lower levels of significance are indicated in the relevant table. The residuals were independent of age.

\section{Results}

\section{SUBJECTS}

Mean values and ranges for the primary lung function indices are summarised in table 1 , and co-linearity between some variables is indicated in table 2. The indices BMI and FFMI were independent of stature in men, and in women BMI and stature were weakly correlated $(r=-0.21)$. In both sexes fat $\%$ and, to a lesser extent, FFMI, BMI and stature were significantly correlated with age.

\section{VARIANCE EXPLAINED BY LINEAR REGRESSION} MODELS

Contributions of $B M I$

After adjusting for age and stature, use of BMI as a reference variable reduced the residual standard deviations about the equations and correspondingly increased the variance explained by the regressions for all the primary lung function indices in women, and for some in men. The exceptions were TLC, FEV FVC, and RV. The increases in explained variance exceeded $33 \%$ for IC, ERV, and FRC (table 3). Among the indices that were ratios, use of BMI improved the descriptions of KCO in both sexes but not the descriptions of $\mathrm{RV} \%$ (RV/TLC) or FEV\% ( $\left.\mathrm{FEV}_{1} / \mathrm{FVC}\right)$.

\section{Contributions of fat $\%$ and FFMI}

For indices where BMI contributed to the description of the lung function, the contributions made by the two components fat $\%$ and FFMI were similar. In addition, fat $\%$ and FFMI improved the descriptions of TLC, FVC, $\mathrm{FEV}_{1}$, and RV in men (table 3). In the case of TLCO and KCO the contributions were similar whether or not allowance was made for alveolar volume. Body composition did not contribute to $\mathrm{RV} \%$ or $\mathrm{FEV} \%$.

Where fat made a significant contribution its sign was negative in that it reduced the size of the index under consideration. Fat $\%$ did not contribute to IC, TLCO, or KCO. FFMI made a positive contribution to these indices and also to TLC, FVC, and $\mathrm{FEV}_{1}$ in men. In both sexes additional muscle was associated with lower values for ERV and FRC. Hence, for these indices the effects of fat and muscle reinforced each other and so could be described by BMI. 
Table 3 Linear equations for primary indices of lung function including terms for body composition

\begin{tabular}{|c|c|c|c|c|c|c|c|c|}
\hline \multirow[t]{2}{*}{ Index } & \multicolumn{5}{|c|}{ Partial regression coefficients } & \multirow[t]{2}{*}{ Constant } & \multirow[t]{2}{*}{$R S D^{\star}$} & \multirow[t]{2}{*}{ Variance $^{\star}$} \\
\hline & Aget & Stature & $B M I \ddagger$ & Fat $\%$ & FFMI & & & \\
\hline \multicolumn{9}{|l|}{ TLC } \\
\hline Women & NS & 7.82 & & -0.038 & NS & -5.92 & $0.52(0.54)$ & $0.61(0.56)$ \\
\hline Men & 0.025 & 9.64 & & -0.051 & 0.058 व & -11.1 & $0.64(0.67)$ & $0.47(0.42)$ \\
\hline \multicolumn{9}{|l|}{ IC } \\
\hline Women & NS & 3.84 & & NS & 0.084 & -5.06 & $0.36(0.38)$ & $0.40(0.31)$ \\
\hline Men & NS & 3.44 & & NS & 0.13 & -5.16 & $0.48(0.53)$ & $0.28(0.12)$ \\
\hline \multicolumn{9}{|l|}{ FRC } \\
\hline Women & NS & 4.06 & -0.090 & & & -1.46 & $0.46(0.56)$ & $0.53(0.29)$ \\
\hline Men & 0.019 & 5.95 & -0.086 & & & -5.53 & $0.59(0.64)$ & $0.39(0.26)$ \\
\hline \multicolumn{9}{|l|}{ ERV } \\
\hline Women & -0.018 & 1.40 & -0.058 & & & 1.19 & $0.33(0.39)$ & $0.58(0.41)$ \\
\hline Men & NS & 3.69 & -0.079 & & & -2.57 & $0.46(0.50)$ & $0.37(0.24)$ \\
\hline \multicolumn{9}{|l|}{ RV } \\
\hline Women & 0.024 & 2.56 & & -0.025 & NS & -2.63 & $0.30(0.32)$ & $0.41(0.32)$ \\
\hline Men & 0.033 & 2.57 & & -0.017 & NS & -3.81 & $0.33(0.34)$ & $0.37(0.34)$ \\
\hline \multicolumn{9}{|l|}{ FVC } \\
\hline Women & -0.018 & 4.84 & & -0.030 & NS & -2.57 & $0.46(0.47)$ & $0.61(0.58)$ \\
\hline Men & -0.011 & 6.76 & & -0.047 & 0.069 & -6.70 & $0.52(0.55)$ & $0.55(0.50)$ \\
\hline \multicolumn{9}{|l|}{$\mathrm{FEV}_{1}$} \\
\hline Women & -0.022 & 3.05 & & -0.022 & NS & -0.47 & $0.35(0.37)$ & $0.66(0.63)$ \\
\hline Men & -0.026 & 4.80 & & -0.031 & 0.041 & -3.61 & $0.48(0.49)$ & $0.57(0.54)$ \\
\hline \multicolumn{9}{|l|}{ TLCO } \\
\hline Women & -0.030 & 7.47 & $2.54 \ddagger$ & NS & 0.209 & -9.68 & $1.23(1.26)$ & $0.44(0.40)$ \\
\hline Men & -0.072 & 10.49 & $2.71 \ddagger$ & NS & $0.12 \uparrow$ & -11.98 & $1.33(1.34)$ & $0.48(0.47)$ \\
\hline
\end{tabular}

TLC = total lung capacity; IC = inspiratory capacity; FRC = functional residual capacity; ERV = expiratory reserve volume; RV = residual volume; $\mathrm{FVC}=$ forced vital capacity; $\mathrm{FEV}_{1}=$ forced expiratory volume in one second; $\mathrm{TLCO}_{\mathrm{L}}=$ carbon monoxide transfer factor; NS = not significant and variable omitted on this account.

*Term without allowance for body composition is given in parentheses. In each instance the difference is significant.

†Effects on partial regression coefficients on age of allowing for fat $\%$ and FFMI age are given in table 5.

$¥$ In case of TLCO the coefficient is that on $\mathrm{VA} / \mathrm{St}^{2}$, not BMI.

TCoefficient significant at $5 \%$ but not at $1 \%$ level of probability.

By contrast, for TLC, FVC and $\mathrm{FEV}_{1}$ in men, the contributions of fat and muscle had opposite signs and the terms for BMI were then not significant.

MAGNITUDES OF EFFECTS

Allowance for body composition had a material effect on reference values for subjects whose physique was at the limits of the present observed distributions (high fat and low muscle or vice versa, table 4 ). The deviations compared with making no allowance for body composition were in the range 0.3-2.3 SD about the levels predicted using the conventional regression equation based on age and stature alone.

PARTIAL REGRESSION COEFFICIENTS ON AGE With the exception of IC, the primary lung function indices were related to age. All of them were related to stature. In the presence of stature the partial regression coefficients on age were not modified by additional allowance for BMI. By contrast, after allowing for fat $\%$ and
FFMI, most partial regression coefficients for lung volume on age were increased-that is, they became less negative, more positive, moved from negative to NS, or from NS to positive (figs 1 and 2). The changes in men were significant for $\mathrm{FEV}_{1}$ and FVC $(\mathrm{n}=383)$ and approached significance for FRC $(n=186)$; none were significant in women $(n=97)$. The age coefficients for TLCO and KCO were not modified in either sex.

\section{DIFFERENCES BETWEEN THE SEXES}

\section{Linear model}

The mean values for indices of lung function differed between men and women (table 1). For ERV, the sex difference was related to the men being taller and was eliminated when allowance was made for stature. For the remaining indices the sex difference persisted after making linear allowances for age and stature (table 5). For TLC, IC, and FVC the sex differences were independent of age; the differences were unaltered after making allowance for BMI but were eliminated when allowances

Table 4 Changes in reference values associated with the subject having a body composition at the limits of the observed ranges (from tables 1 and 3)

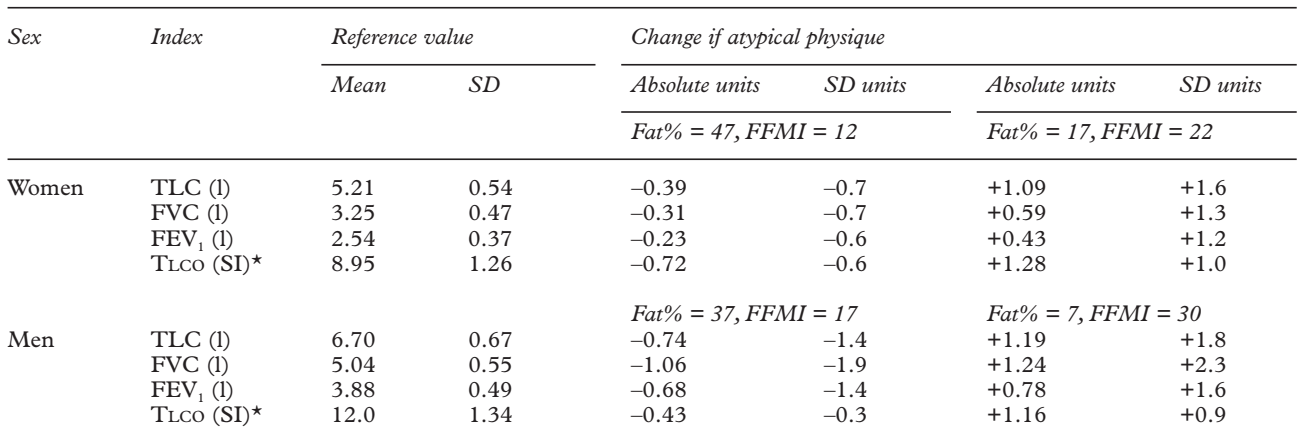

*SI units: $\mathrm{mmol} / \mathrm{min} / \mathrm{kPa}$. 


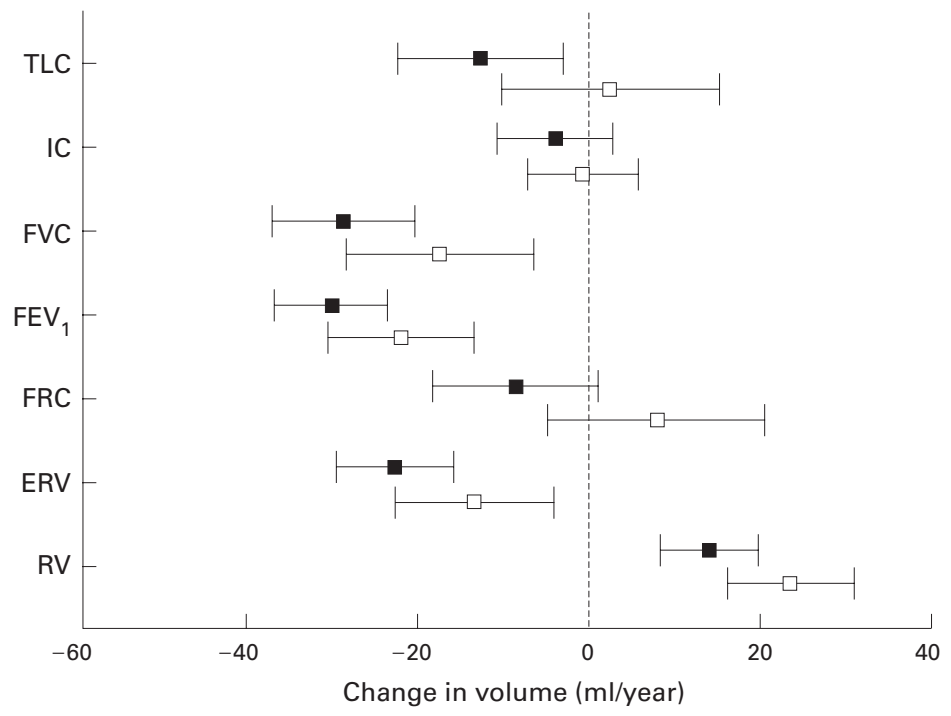

Figure 1 Mean values and 95\% confidence intervals for partial regression coefficients of indices of lung volume on age, without and with allowance for fat $\%$ and FFMI (closed and open squares, respectively) in women.

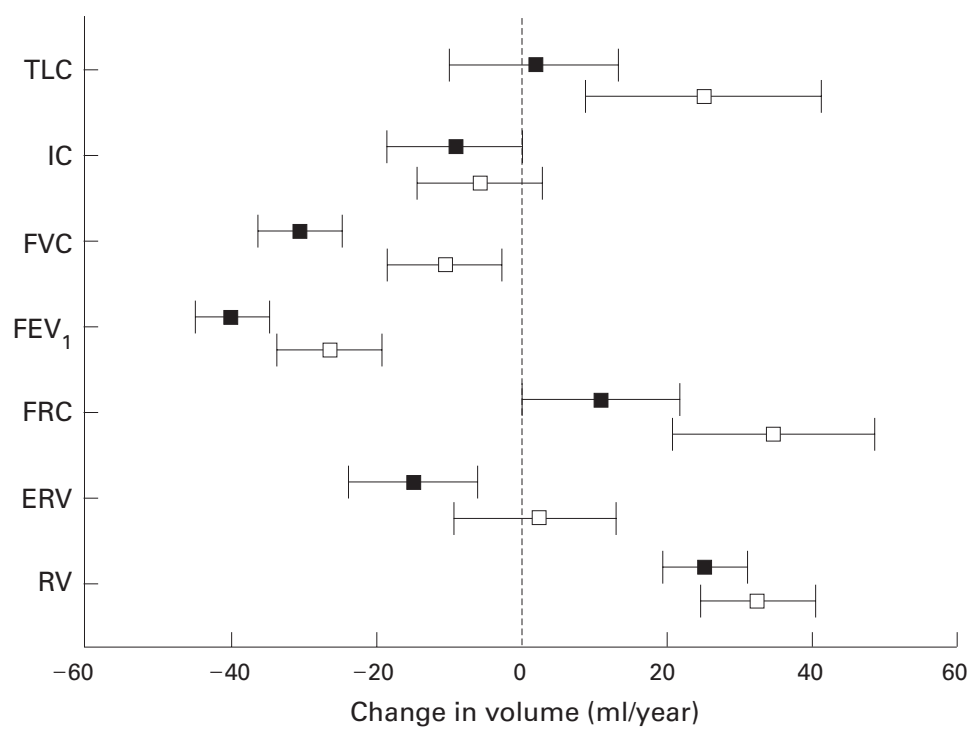

Figure 2 Mean values and 95\% confidence intervals for partial regression coefficients of indices of lung volume on age, without and with allowance for fat $\%$ and FFMI (closed and open squares, respectively) in men.

Table 5 Effect of allowing for fat\% and/or FFMI on the partial regression coefficients on sex in the presence of terms for age, stature and, in the case of TLCO, VA/St: combined data for men and women

\begin{tabular}{|c|c|c|c|}
\hline \multirow[b]{2}{*}{ Index* } & \multicolumn{2}{|c|}{ Mean (SE) coefficient on sext } & \multirow{2}{*}{$\begin{array}{l}\text { After allowing for body composition } \\
\text { does sex term remain significant? }\end{array}$} \\
\hline & No allowance & Allowance & \\
\hline \multicolumn{4}{|c|}{ No age/sex interaction, hence linear model used: } \\
\hline TLC (1) & $0.31(0.111)$ & {$[-0.14(0.151)]$} & No \\
\hline FVC (1) & $0.72(0.080)$ & {$[0.049(0.147)]$} & No \\
\hline IC (1) & $0.51(0.088)$ & {$[0.027(0.111)]$} & No \\
\hline ERV (l) & {$[0.09(0.068)]$} & {$[-0.08(0.119])$} & NS without allowance \\
\hline \multicolumn{4}{|c|}{ Significant linear age/sex interaction, hence proportional model used: } \\
\hline $\mathrm{FEV}_{1}(\%)$ & $16.3(2.18)$ & $10.6(2.66)$ & Yes \\
\hline FRC (\%) & {$[-6.7(3.64)]$} & {$[-7.7(5.91)]$} & NS without allowance \\
\hline RV (\%) & $-20.1(4.07)$ & $-31.1(5.02)$ & Yes \\
\hline TLCO $(\%)$ & $6.3(2.36)$ & {$[-1.3(3.27)]$} & No \\
\hline
\end{tabular}

^Numbers of subjects are given in table 1 .

tSex term $=1$ for males and $=0$ for females

[] coefficient not different from zero $(\mathrm{p}>0.05)$

Abbreviations are as in the footnote to table 3. were made for fat $\%$ and/or FFMI. With the linear model the sex differences for $\mathrm{FEV}_{1}$, FRC, RV, and TLCO varied with age.

\section{Proportional model}

Compared with the linear model, changing to the proportional model did not materially alter the proportions of variance explained by the regressions (mean $R^{2}$ values for 12 indices using the two models $=0.57$ and 0.54 , respectively). However the age/sex interaction terms and the sex differences in FRC and KCO were eliminated. Making allowances for fat $\%$ and FFMI now led to the term for sex no longer being significant for TLCO (table 5).

\section{Discussion}

APPROPRIATENESS AND QUALITY OF THE DATA

In the absence of random samples from populations, no two groups of men and women can be completely comparable. In the present instance the subjects were healthy and reasonably active; obese and asthenic physiques may have been underrepresented. The methods, indices, and models used for the analysis were standard ones. The data for women have provided regression equations on age and stature that are widely used, ${ }^{2}$ and the equations for men are similar to those so used. ${ }^{1}$ Extension of the analyses to include body composition, measured by a standard method, should therefore also be reliable.

PREVIOUS RELEVANT STUDIES

Body mass was used in many early studies but was not standardised for stature. Mass standardised as BMI has been used infrequently. ${ }^{17}{ }^{18}$ An allowance for fat expressed as relative weight was used by Amrein and colleagues ${ }^{19}$ and led to results not dissimilar to the present ones. Only a few reference values have included fat $\%$ and FFMI. ${ }^{12}{ }^{14}{ }^{1520}$ A logarithmic model to describe the effects of sex was suggested by Cole $^{21}$ and applied by Dirksen and Groth. ${ }^{22}$ Its use eliminated sex differences for VC, RV, $\mathrm{FEV}_{1}$, and TLCo. A different model might have eliminated entirely the need for a sex term but other evidence suggests that increasing the sophistication of a model can yield a diminished return. ${ }^{23}$ Cole's model did not include body composition.

CONTRIBUTIONS OF FAT\%, FFMI AND BMI In the present study the amounts of body fat and muscle exerted independent effects on the lung function. Fat \% contributed to RV and ERV, and hence to FRC, VC and TLC, all with a negative sign, suggesting displacement of air by fat within the thorax and abdomen. Contrary to expectations, the contribution of fat $\%$ did not differ between the sexes, possibly because very fat women were not included in the study population.

In both sexes FFMI contributed significantly to IC and TLCO (and hence to KCO), whereas fat $\%$ did not. The contribution to TLCO and Kco possibly reflected dimensional symmetry in the oxygen transport chain from air to muscles. ${ }^{24}$ The contribution to IC and to volumes that included IC was probably due to FFMI 
reflecting the strength of respiratory muscles with which it was correlated in the present male subjects. ${ }^{25}$ Muscle strength was not measured in the women.

In both sexes FFMI contributed to ERV and hence to FRC, but the sign was negative, the same as that on fat $\%$. As a result the contributions of the two indices to FRC were synergistic and adequately represented by BMI. This finding suggested an association between quantity of muscle, respiratory muscle tone, and the resting respiratory level.

In men the contribution of FFMI to IC exceeded that to ERV so the overall effect on FVC was positive, the opposite to that of fat $\%$. In this circumstance the indices FVC, TLC and $\mathrm{FEV}_{1}$ could be described using FFMI and fat $\%$ but not using BMI. By contrast, in women the mean contributions of FFMI to IC and ERV were of approximately equal magnitudes. The two effects were of opposite signs so they cancelled out those indices that contained both terms. Hence, unlike in men, in women TLC, FVC, and $\mathrm{FEV}_{1}$ could be described using either fat $\%$ as in table 3, or BMI. The latter term might not be appropriate for women who take much exercise as the effect of muscle on IC could then predominate. BMI also contributed to TLCO and KCO where it represented mainly FFMI, and to RV in women where it represented mainly fat $\%$.

\section{REFERENCE VALUES THAT INCLUDE BODY}

COMPOSITION

Reference values based on age and stature do not detect variations in lung function attributable to an unusual physique such as a high fat $\%$ and low FFMI or vice versa, yet such variations can be up to $2 \mathrm{SD}$, sufficient to affect diagnosis. There is therefore a place for reference values that take account of body composition. Body mass index has been proposed ${ }^{18}$ but its use is only valid for lung function indices where the contributions of fat and muscle are synergistic (have the same sign). For other indices in men, allowance using BMI is significantly less accurate than using fat $\%$ and FFMI. In the present study the outcomes in women by the two approaches were not different, but they might have become so if very overweight or muscular women had been included in the sample. Accordingly, the reference equations for FRC and ERV in table 3 include BMI, but for the other indices the equations are on fat $\%$ and/or FFMI. A full set of equations is available on request to Coterie@globalnet.co.uk.

IMPLICATIONS FOR REGRESSION COEFFICIENTS ON AGE

Age was strongly correlated with fat $\%$ (table 2 ), hence some of the apparent deterioration in lung function with age was due to the older subjects being fatter. As a result, allowing for fat $\%$ modified the age coefficients for those indices to which fat $\%$ made a significant contribution. The trend was consistent across all the indices and both sexes (figs 1 and 2); it was significant for $\mathrm{FEV}_{1}$ and FVC in men where the numbers of subjects were larger than for the other comparisons (table 1). For most indices the apparent changes were to the magnitude of the age coefficients. For TLC there appeared also to be a change in sign; this was from zero to positive in men and from negative to zero in women. If confirmed, this finding removes the anomaly that, while the lung elastic recoil pressure decreases and hence the lung size might be expected to increase with age, the cross sectional age coefficient for TLC in most published reference equations is either zero or negative. The principal exception is studies by the radiographic method where a technical explanation is possible. In the only previous study of directly measured TLC in which an increase with age was observed, the subjects included young persons in the age range 15-25 years amongst whom the age coefficient is known to be positive and this could have influenced the result. ${ }^{26}$ The finding of an increase in TLC with age in male non-smokers is conceptually important and needs to be verified by longitudinal observations.

Making allowance for body composition reduces the environmental component of the trend in lung function with age viewed cross sectionally. The remaining differences more nearly reflect biological ageing of the lung; this is less than may be deduced from conventional cross sectional analyses and more consistent with that observed longitudinally. ${ }^{15}$

IMPLICATIONS FOR REGRESSION COEFFICIENT ON SEX

The mechanical properties of the lungs are basically similar for men and women, ${ }^{27}$ so the overall differences between the sexes might be expected to be small. However, when the present data for the two sexes were combined and regressed linearly on age and stature, the term for sex or age $\times$ sex was significant for every index except ERV. For TLC, IC, and FVC, where sex was significant but age $\times$ sex was not, the sex difference was fully accounted for by the men having, on average, more muscle and less fat than the women. For the remaining indices the need for an interaction term was eliminated when the proportional model was used. With this model the differences for FRC and TLCO were eliminated, respectively, without and with allowance being made for body composition. In the latter comparison the term for muscle may have been a surrogate for haemoglobin concentration. The sex differences persisted for $\mathrm{FEV}_{1}$ and RV; the present findings did not throw light on the possible mechanisms.

As well as being of theoretical interest, combined reference equations for men and women could be helpful where a small group of men and women is exposed to an unusual environment. In this circumstance a proportional model is more generally applicable than a linear one.

IMPLICATIONS FOR ATHLETIC PROWESS

Subjects with little fat but much muscle usually take an above average amount of exercise so respiratory muscle strength might contribute to their lung function independently of FFMI. 
This could not be tested for the whole population but, in the presence of FFMI, the score for habitual activity was not significant.

The finding that men and women have similar lung function after making allowance for body composition has implications for sex related differences in exercise performance. The latter differences would appear to be mainly due to men being taller and having a larger quantity of muscle not, as has recently been suggested, to athletic women having intrinsically smaller lungs. ${ }^{28}$

PRACTICAL CONSIDERATIONS

Allowance for body composition can improve the accuracy and biological relevance of reference equations for lung function. This suggests that the measurement should form part of the repertoire of any comprehensive lung function laboratory, especially one that also undertakes exercise tests. ${ }^{2}$

A laboratory making the new measurements might start by including them in the initial assessments of ambulant patients. In this way, optimal results would be obtained and experience gained which, depending on the clientele, could lead to a selective approach being adopted. Body mass index is of limited usefulness so the procedure should include fat $\%$ and FFMI. Sophisticated methods can be used ${ }^{29}$ but for a lung function laboratory the skinfold method is recommended as it is simple, can be applied to all subjects, and is reasonably accurate (SEE in our laboratory $<4 \%$ ). Alternatively, fat can be estimated from the distribution of electrolytes obtained by a bioelectrical impedance method but this method has theoretical disadvantages. ${ }^{30}$ Training in the chosen method is essential if optimal results are to be obtained.

The authors thank Mr Paul Finn (Postgraduate Institute for Health, School of Health, University of Teesside) for statistical Health, School of Health, University of Teesside) for statistical Sciences, University of Newcastle upon Tyne) kindly provided Sciences, University of Newcastle upon
facilities and also visitor status for JEC.

Supported by the University of Newcastle upon Tyne. No conflict of interest.

1 Quanjer PhH, ed. Standardized lung function testing. Bull Eur Physiopathol Respir 1983;19(suppl 5):1-95.

2 Cotes JE. Lung function: assessment and application in Cotes JE. Lung function: assessment and application in
medicine. 5th ed. Oxford: Blackwell Scientific Publications, 1993.

3 American Thoracic Society. Lung function testing; selection of reference values and interpretative strategies. Am Rev Respir Dis 1992;145:1202-18.

4 Durnin JVGA, Womersley J. Body fat assessed from total body density and its estimation from skinfold thickness: measurements on 481 men and women aged from 16 to 72 years. Br F Nutr 1974;32:77-97.
5 Sue DY. Obesity and pulmonary function, more or less? Chest 1997;111:844-5.

6 Ashwell M, Cole TJ, Dixon AK. Obesity: new insight into the anthropometric classification of fat distribution shown by computed tomography. BMF 1985;290:1692-4.

7 Chen Y, Horne SL, Doseman JA. Body weight and weight gain related to pulmonary function decline in adults: a six year follow up study. Thorax 1993;48:375-80.

8 Lazarus R, Gore CJ, Booth M, et al. Effects of body composition and fat distribution on ventilatory function in adults. Am $\mathcal{F}$ Clin Nutr 1998;68:35-41.

9 Leith DE, Bradley M. Ventilatory muscle strength and endurance training. F Appl Physiol 1976;41:508-16.

10 Davey IS, Cotes JE, Reed JW. Relationship of ventilatory capacity to hyperbaric exposure in divers. I Appl Physiol 1984;56:1655-8.

11 Weiner P, Waizman J, Weiner M, et al. Influence of excessive weight loss after gastroplasty for morbid obesity on respiratory muscle performance. Thorax 1998;53:39-42.

12 Hall AM, Heywood C, Cotes JE. Lung function in healthy British women. Thorax 1979;34:359-65.

13 Schoenberg JB, Beck GJ, Bouhoys A. Growth and decay of pulmonary function in healthy blacks and whites. Respir Physiol 1978;33:367-93.

14 Cotes JE, Dabbs JM, Hall AM, et al. Sitting height, fat free mass and body fat as reference variables for lung function in healthy British children: comparison with stature. Ann Hum Biol 1979; 6:307-14.

15 Chinn DJ, Cotes JE, Reed JW. Changes in body mass can affect interpretation of longitudinal measurements of ventilatory capacity $\left(\mathrm{FEV}_{1}\right.$ and FVC). Thorax 1996;51: 699-704.

16 Chinn DJ, Cotes JE, Flowers R, et al. Transfer factor (diffusing capacity) standardised for alveolar volume; validation, reference values and applications of a new linear model to replace Kco (Tl/VA). Eur Respir 7 1996;9:126977 .

17 Jenkins SC, Moxham J. The effects of mild obesity on lung function. Respir Med 1991;85:309-11.

18 Pistelli F, Bottai M, Viegi G, et al. Smooth reference equations for slow vital capacity and flow-volume curve indices. Am f Respir Crit Care Med 2000;161:899-905.

19 Amrein R, Keller R, Joos H, et al. Valeurs theoriques nouvelles de l'exploration de la fonction ventilatoire du poumon. Bull Physiopathol Respir 1970;6:317-49.

20 Mengesha YA, Mekonnen Y. Spirometric lung function tests in normal non-smoking Ethiopian men and women. Thorax 1985;40:465-8 (correction: 1986;41:223).

21 Cole TJ. The influence of height on the decline in ventilatory function. Int $\mathcal{F}$ Epidemiol 1974;3:145-52.

2 Dirksen A, Groth S. Calculation of reference values for lung function tests. Bull Eur Physiopathol Respir 1986;22:231-7.

23 Rosen MJ, Sorkin JD, Goldberg AP, et al. Predictors of agerelated decline in maximal aerobic capacity: a comparison of four statistical models. $\mathcal{F}$ Appl Physiol 1998;84:2163-70.

24 Holmgren A, Astrand P-O. DL and the dimensions and functional capacities of the $\mathrm{O}_{2}$ transport system in humans. f Appl Physiol 1966;21:1463-70.

25 Chinn DJ, Cotes JE, El-Gamal FM, et al. Respiratory health of young shipyard welders and other tradesmen studied cross-sectionally and longitudinally. Occup Environ Med 1995;55:33-42.

26 Crapo RO, Morris AH, Gardner RM. Reference spirometric values using techniques and equipment that meet ATS recommendations. Am Rev Respir Dis 1981;123:659-64.

27 Gibson GJ, Pride NB, O'Cain C, et al. Sex and age differences in pulmonary mechanics in normal nonsmoking subjects. F Appl Physiol 1976;41:20-5.

28 McClaran SR, Harms CA, Pegelow DF, et al. Smaller lungs in women affect exercise hyperpnoea. F Appl Physiol 1998; 84:1872-81.

29 Jones PRM, Norgan NG. Anthropometry and the assessment of body composition. In: Harries M, Williams C, Stanish WD, Micheli LJ, eds. Oxford textbook of sports medicine. 2nd ed. Oxford: Oxford University Press, 1998: 207-21.

30 Norgan NG. The assessment of body composition of populations. In: Davies PSW, Cole TJ, eds. Body composition techniques in health and disease. Society for the Study of Human Biology Symposium Series 36. Cambridge: Cambridge University Press, 1995: 195-221. 